\title{
VPLIV KADROVSKEGA MENEDŽMENTA NA KREPITEV VARNOSTNE KULTURE V KORPORATIVNOVARNOSTNEM OKOLJU
}

Povzetek Posameznik se je kot socialno bitje v marsičem spremenil in s stališča zaposlenega v posamezni organizaciji postal izredno zahteven ter zazrt skoraj izključno v zadovoljevanje svojih potreb, ki jih postavlja daleč pred potrebe organizacije v širšem in ožjem smislu. To med drugim pomeni, da smo zaradi dinamičnega in prožnega trga delovne sile prišli v stanje hitrega menjavanja zaposlitev in s tem delovnih okolij, v katerih je v tako kratkem času pri posameznikih nemogoče vzpostaviti ustrezno pripadnost ožjemu kolektivu in organizaciji v širšem pomenu besede. To pred vodilni menedžment organizacij, in še posebno pred korporativnovarnostne strokovnjake, postavlja zahtevne izzive, kako v globalnem ekonomskem okolju, ki temelji na hudi konkurenčni tekmovalnosti, zagotoviti ustrezno varovanje pomembnih poslovnih informacij, do katerih dostopajo zaposleni v posameznih organizacijah. Iz analize odgovorov, pridobljenih z intervjuji, je razvidno, da različne organizacije v svojih okoljih pomen celovitega obvladovanja varnostnih tveganj in še posebno pomen varnostne kulture različno dojemajo in se zaradi svojih posebnosti te problematike tudi zelo različno lotevajo.

Ključne besede

\section{Kadrovski menedžment, varnostna kultura, obvladovanje tveganj, korporativno- varnostni menedžment.}

Individuals as social beings have changed in many aspects. As employees of individual organisations, they have become extremely demanding and focused almost exclusively on the satisfaction of their own needs, which they place far ahead of the organisation's needs in the broad and narrow sense. This also means that the dynamic and flexible labour market has generated a situation of quick job changes and, consequently, working environments, where individuals find it is impossible to establish adequate affiliation to their immediate colleagues and the organisation in general. Leading management in organisations, especially corporate security experts are thus confronted with a demanding challenge of how to provide adequate protection of 
critical business information accessible to employees of individual organisations in a severely competitive environment. The analysis of acquired interview results has shown that different organisations have different perceptions of security risk management, especially the importance of security culture, and due to their respective specifics adopt different approaches to address this problem.

\section{Keywords}

\section{Human resource management, security culture, risk management, corporate-se- curity management.}

Uvod Varnost ni pomembna dobrina samo za razvoj posameznika in družbe, temveč je ustrezno varnostno okolje nujno tudi za nemoteno delovanje večnacionalnih korporacij. Predvsem načini in oblike organiziranega zagotavljanja varnosti so se skozi zgodovino s pomembnim vplivom vedno novih tehnologij in znanstvenih spoznanj drastično spreminjali (Čaleta, 2011). Globalizacija sveta in s tem posredno globalizacija varnosti postavljata sodobno družbo pred zahtevna vprašanja, in sicer, kako še naprej graditi svoj razvoj na temeljnih postulatih prostega pretoka blaga, storitev in ljudi ter na drugi strani grožnje obvladovati na sprejemljivi ravni tveganja. Varnostno okolje 21. stoletja postaja vse bolj zapleteno in dinamično (Borodzicz, 2005, str. 18). Tveganja in grožnje so zaradi svoje asimetričnosti pojavljanja postali obremenjujoči za nemoteno delovanje sodobne družbe. Če v tem kontekstu upoštevamo tudi vedno močnejšo odvisnost družbe od delovanja tehnoloških dosežkov moderne dobe, kot so informacijsko-komunikacijska tehnologija, električna energija in drugi energenti, lahko z gotovostjo trdimo, da je družba prav zaradi te odvisnosti še bolj izpostavljena tveganjem oziroma je o stanju popolne varnosti iluzorno razmišljati. Vsi ukrepi na nacionalni in mednarodni ravni so samo ukrepi za zagotavljanje tako imenovane zmerne stopnje tveganja, ki je v razmerju do operativnosti delovanja družbe v nekem ravnotežju. Toda v tem celovitem sistemu nikakor ne smemo in ne moremo zanemariti človeškega dejavnika kot temeljnega potenciala vsake moderne organizacije. Tako kot je po eni strani človeški potencial temelj vsakega družbenega in v tem okviru tudi organizacijskega okolja, pa je po drugi strani prav človeški dejavnik najšibkejši člen tega sistema, ki ga je nemogoče popolnoma nadomestiti s posameznimi tehnološkimi sistemi. Bertoncelj (2012, str. 129) ugotavlja, da je posameznik pomemben referent pojma varnosti. Varnost posameznika obravnavajo različne teorije s področja družbenih, psiholoških in varnostnih študij, v ospredje je varnost posameznikov postavljena tudi v konceptu humane varnosti, kot so ga razvili v okviru OZN (UNDP, 2011 v Bertoncelj, 2012).

Posameznik in družba sta stalno izpostavljena številnim virom ogrožanja. Številni so naravno pogojeni, veliko pa je tudi takih, ki so posledica procesov, ki potekajo v družbi in so odsev njenega ekonomskega, socialnega in tehnološkega razvoja. Posamezniki so vsak dan izpostavljeni različnim vplivom, ki jih bolj ali manj ogrožajo in predstavljajo stalno tveganje za njihovo fizično, psihično, duhovno in materialno varnost. Zaradi navedenega se je v organizacijskem okolju treba zavedati, da trenutno temu dejavniku namenjamo vse premalo sistemske pozornosti. 
Posameznik se je kot socialni agregat v marsičem spremenil in s stališča zaposlenega v posamezni organizaciji postal izredno zahteven in zazrt skoraj izključno v zadovoljevanje svojih potreb, ki jih postavlja daleč pred potrebe organizacije v širšem in ožjem smislu. To med drugim pomeni, da smo zaradi dinamičnega in prožnega trga delovne sile prišli v situacijo hitrega menjavanja zaposlitev in s tem delovnih okolij, kjer je v tako kratkem času pri posameznikih nemogoče vzpostaviti ustrezno pripadnost ožjemu kolektivu in organizaciji v širšem pomenu besede. To pred vodilni menedžment organizacij in še posebno pred korporativnovarnostne strokovnjake postavlja zahtevne izzive, kako v globalnem ekonomskem okolju, ki temelji na hudi konkurenčni tekmovalnosti, zagotoviti ustrezno varovanje pomembnih poslovnih informacij, do katerih dostopajo zaposleni v posameznih organizacijah. Seveda je prvi logični odgovor v smeri krepitve varnostne kulture, ki pa ima to »pomanjkljivost«, da je dolgotrajnejši proces, kot bi si v teh dinamičnih časih želeli. Drugo dejstvo pa je, da bo treba sistemske pristope v korporacijskem okolju prilagoditi v smeri teh dinamičnih sprememb modernega okolja. V tem okviru si je danes težko predstavljati, da vodilni menedžment organizacij v celoti ne uporablja vseh sistemskih vzvodov za obvladovanje tveganj za delovanje njihove organizacije. To pomeni, da kadrovski menedžment in korporativnovarnostni menedžment prepleteno izvajata in se vključujeta $\mathrm{v}$ proces, ki ga v našem obravnavanem primeru lahko umestimo v zagotavljanje ustrezne stopnje varnostne kulture zaposlenih v tej organizaciji. Ustrezna izbira kadrovskega potenciala, stalno preverjanje okoliščin in znakov, ki bi lahko pri najpomembnejših kadrih organizacije pomenili določena tveganja za odtekanje pomembnih informacij, so postali pomembni sistemski pogoji pri izbiri zaposlenih, predvsem tistih na najpomembnejših delovnih mestih v organizaciji. V tem delu je treba poudariti tudi pomen varovanja človekovih pravic in zasebnosti posameznikov. Dejstvo je, da se na tem področju pravna praksa ustrezne meje med dopustnimi posegi delodajalca v zasebnost zaposlenega še vedno oblikuje. To dokazujejo tudi odločbe informacijskih pooblaščencev v državah Evropske unije in ne nazadnje tudi evropska zakonodaja ter smernice s tega področja. Velike večnacionalne korporacije danes namreč močno presegajo nacionalne meje, zato je ustrezen skupen pristop do te problematike še kako pomemben.

\section{PREGLED LITERATURE IN TEORETIČNA IZHODIŠČA ZA PROUČEVANI PREDMET}

V prispevku bomo poskušali analizirati in temeljito oceniti vpliv kadrovskega menedžmenta na krepitev varnostne kulture v korporativnovarnostnem okolju. Vzvodi kadrovskega menedžmenta so namreč tisti del upravljavskih mehanizmov v organizacijah, skozi katerega lahko lastniki ali vodje bistveno vplivajo na stopnjo varnostne kulture.

Ključno vprašanje, ki se postavi samo po sebi, je, kateri so tisti dejavniki, ki vplivajo na stopnjo razvoja posamezne družbe, oziroma kateri so tisti dejavniki, ki posameznim družbam omogočajo, da se v primerjavi z drugimi hitreje razvijajo. Danes, v pogojih globalizacije, se vse bolj zavedamo pomena znanja, ki je in vse bolj postaja 
najpomembnejši dejavnik razvoja gospodarstva in s tem celotne družbe. Delovanje podjetja je v zahtevnem globalnem okolju neposredno povezano z učinkovitim izvajanjem korporativne varnosti, s katerim organizacija ali podjetje zagotavlja obvladovanje in upravljanje varnostnih in drugih s tem povezanih tveganj (Čaleta, 2012). Tveganje postaja nov ključ skupnih interesov v poslovnem svetu in od poslovodstva zahteva visoko stopnjo korporacijske odgovornosti. Organizacije se pri svojem delovanju spoprijemajo s celim nizom tveganj in jih v osnovi lahko ločimo na zunanja tveganja, tveganja zaradi notranjih dejavnikov ter kombinacijo obeh.

Kljub hitremu tehnološkemu razvoju človek ostaja tisti del, ki ima v procesu obvladovanja varnostnih tveganj bistveno vlogo in v večini primerov še vedno predstavlja najšibkejši člen v celovitem sistemskem zagotavljanju varnosti. Odtekanje najpomembnejših poslovnih informacij in poslovnih skrivnosti ter s tem povezani socialni inženiring, malomarnost, nizka organizacijska in varnostna kultura, neizobraženost in namerno izvajanje protizakonitih aktivnosti so dejavniki, ki zaradi obvladovanja varnostnih tveganj silijo podjetja k učinkovitejšemu izvajanju ukrepov korporativne varnosti, povezane $\mathrm{z}$ nadzorom zaposlenih $\mathrm{v}$ njihovih temeljnih delovnih okoljih

(Lobnikar, Čaleta, Žaberl, Anžič, Rančigaj, 2009). Naslednji pomemben dejavnik, na katerega moramo biti še posebno pozorni pri zagotavljanju korporativne varnosti, so zunanji izvajalci in pogodbeni partnerji, ki lahko za delovanje organizacije pomenijo visoko stopnjo tveganja. V zadnjem obdobju podjetja vedno bolj prenašajo nekatere procese na zunanje pogodbene izvajalce v obliki »outsorcinga« (Vršec, 2010). Pri izračunu stroškov se lahko ta oblika zmanjšanja stroškov delovanja organizacije zdi zelo vabljiva, vendar je treba na proces oddajanja pomembnih funkcij gledati tudi z drugačnega zornega kota, saj to za delovanje organizacije pomeni zelo veliko tveganje, ki se ga lastniki in menedžment ne zavedajo. S prenosom nekaterih procesov na zunanje izvajalce izpostavljamo organizacijo tveganju, ki se izraža predvsem v preveliki odvisnosti od pogodbenih izvajalcev, v dostopu nepooblaščenih oseb do pomembnih poslovnih informacij, ki pomenijo konkurenčno prednost pred drugimi konkurenti, in v drugih oblikah nevarnosti. Tveganje lahko zmanjšamo tako, da od pogodbenih izvajalcev zahtevamo izpolnjevanje minimalnih standardov, ki jih imamo v organizaciji opredeljene v okviru ukrepov za zagotavljanje korporativne varnosti.

Za učinkovito razumevanje obravnavane problematike je treba izpostaviti tri temeljne pojme, ki jih bomo v nadaljevanju tudi podrobneje opredelili, in sicer kadrovski menedžment, korporativnovarnostni menedžment in varnostna kultura.

\section{Kadrovski menedžment}

Kadrovski menedžment v neki organizaciji je tisti del upravljavskega mehanizma, na podlagi katerega lahko lastniki ali vodje organizacije bistveno vplivajo in pripomorejo k stopnji varnostne kulture, kar je tudi pogoj za uspešno zagotovitev ustreznega obvladovanja tveganj. 
Kadrovski menedžment organizacij mora poskrbeti, da vsi zaposleni pri svojem delu dosledno upoštevajo pravne, organizacijske, varnostne in etične vrednote, in sicer z dobro motivacijo delavcev za napredek in izboljšanje učinkovitosti dela ter z vzpostavitvijo delovnega okolja, v katerem so lahko zaposleni čim bolj produktivni in odgovorni.

V strokovni literaturi lahko najdemo zelo široko paleto definicij, povezanih s terminom kadrovski menedžment. Težiščni pojem, povezan s kadrovskim menedžmentom, so kadrovski viri, ki jih ta menedžment tudi upravlja.

Merkač (2005, str. 14) opredeljuje kadrovski menedžment kot »proces, v katerem organizacija sistematično in integrirano s svojo poslovno strategijo načrtuje potrebe po kadrih, kadruje, razvija in vrednoti svoje kadre, jih nagrajuje in z njimi vzdržuje učinkovite odnose«. Institut za kadrovski menedžment je objavil uradno definicijo kadrovskega menedžmenta, ki jo je povzel tudi Cuming (1994, str. 2): »Kadrovski menedžment (personnel management) je del menedžmenta, ki se ukvarja z zaposlenimi in njihovimi odnosi v organizaciji. Njegov namen je ustvariti aktivno organizacijo z razdelitvijo dela ljudem, ki jo sestavljajo. Tako jim omogoča, da čim bolj prispevajo k uspehu organizacije. Kadrovski menedžment se ukvarja s človeškimi in socialnimi posledicami sprememb v organizacijah in načinu dela znotraj organizacij. Ukvarja pa se tudi z ekonomskimi in socialnimi spremembami v skupnosti.« Možina, Jereb, Florjančič in Svetic (1998, str. 3) ugotavljajo, da se »management nanaša na vodenje, ravnanje in upravljanje človeških virov v organizaciji«.

Možina (2002, str. 7) opredeljuje kadrovske vire kot »zaposlene in njihove sposobnosti znanje, motiviranost, vrednote itd., kakor tudi njihovo navezanost na skupino, organizacijo, pripravljenost na sodelovanje in drugo«. Nekateri avtorji kadrovske vire pojmujejo kot ožji pojem kot »človeške vire«. Lipičnik (1998, str. 34) opredeljuje človeške vire kot »zmožnosti, ki zajemajo vse znane in neznane sposobnosti posameznika. To v širšem smislu pomeni človekove psihične, fizične in fiziološke zmožnosti, v ožjem smislu pa sposobnosti, znanje, spretnosti, osebnostne lastnosti in motivacijo.«

Florjančič in drugi (2004, str. 30) kot kadrovske vire v širšem smislu obravnava »ljudi, ki v kakršni koli obliki sodelujejo v organizirani obliki človeškega dela, torej delajo v neki organizaciji kot na primer gospodarski, politični, športni itd. So najpomembnejši element vsake organizacije.«

Pestrost terminoloških opredelitev pa pomeni tudi nedorečenost in nejasnost, ki se lahko kaže tudi v napačnem razumevanju ali zamenjevanju pojmov. V tem okviru posebej izpostavljam pogosto zamenjevanje pojmov kadrovski menedžment in menedžment človeških virov. Lipičnik (1998, str. 45) v tem okviru posebej izpostavlja, da so ljudi najprej administrativno vključevali v sistem. Pozneje so ugotovili, da je bolj učinkovito izbrati ljudi, ki so predvsem sposobni timskega dela. V zadnjem obdobju 
pa je proces izrazito usmerjen v dojemanje človeških zmožnosti kot ključnega vira in manj v dojemanje ljudi kot vira (Broder, 2006).

Potreba po povečanju učinkovitosti je organizacije prisilila, da so znotraj kadrovske funkcije največ pozornosti namenjali kadrovskemu menedžmentu. V tem kontekstu je bilo prizadevanje usmerjeno $\mathrm{v}$ učinkovitejše prilagajanje zaposlenih sedanjim tehnološkim procesom in organizacijski strukturi organizacij. Kadrovski menedžment je v tej osnovni funkciji, ki so jo izvajali izključno v kadrovski službi, doživel svoj razmah predvsem v obdobju, ko v okolju ni bilo tako drastičnih dinamičnih sprememb. Nekateri avtorji so klasični koncept dojemali kot »osredotočenost kadrovskih procesov na enem mestu, in sicer v kadrovski službi, na katero so vezali tudi odgovornost za delo z ljudmi ter za stanje kadrov v podjetju« (Florjančič, Jesenko, Pagon, 1991, str. 28). Za to obdobje je značilno, da ni bilo tesnega sodelovanja med najpomembnejšimi procesi v organizaciji, kot na primer med kadrovskimi, finančnimi, proizvodnimi, varnostnimi in drugimi procesi. Zaradi dinamičnega okolja je strateški menedžment hitro spoznal, da se njihove organizacije z rigidno in togo organizacijsko strukturo vedno težje prilagajajo dinamiki sprememb. Osredotočanje samo na tehnološke rešitve ni dalo ustreznih rezultatov, zato so hitro ugotovili, da so človeški viri glavni vir za učinkovito delovanje organizacije.

\section{Korporativnovarnostni menedžment}

Korporativno varnost v podjetju upravlja strateški korporativnovarnostni menedžment, ki izvaja proces skladno z zakonodajo, varnostno politiko organizacije, varnostnimi standardi in tudi oceno ogroženosti. Tako se morata pri celovitem obvladovanju tveganj v organizaciji korporativnovarnostni menedžment in kadrovski menedžment dopolnjevati oziroma eden brez drugega ne moreta zagotoviti dovolj visoke stopnje varnostne kulture.

Glavna področja, ki jih obsega korporativna varnost, so »varnost osebja, fizična varnost, informacijska varnost, korporativno upravljanje, izvajanje programov za dvigovanje varnostne kulture in etičnih standardov v organizaciji, odkrivanje in preprečevanje kaznivih dejanj, preprečevanje poneverb, preiskave izrednih dogodkov, krizno upravljanje in odzivanje na krizne dogodke, načrtovanje in zagotavljanje neprekinjenega delovanja in varnost ter zdravje pri delu in varovanje okolja« (Landoll, 2005, str. 108).

Tudi na tem področju v Republiki Sloveniji vlada precejšnja zmeda pri terminološkem opredeljevanju korporativnovarnostne dejavnosti in subjektov, ki to dejavnost neposredno upravljajo v organizacijskih okoljih javnega in zasebnega sektorja.

Vršec (2010, str. 6) opredeljuje varnostni menedžment in ga razvršča v tri skupine:

- državni (varnostni) menedžment - ali bolje (varnostni) menedžment državnih organov, ki upravlja in vodi posamezne državne organe in organe v njegovi sestavi;

- varnostni menedžment v zasebnem varovanju, ki v imenu delodajalcev - zasebnih varnostnih podjetij - nastopa kot ponudnik varnostnih storitev; 
- varnostni menedžment v gospodarskih in drugih organizacijah, ki na trgu varnostnih storitev nastopajo kot naročniki, kupci in porabniki varnostnih storitev.

Čaleta (2011, str. 21) opredeljuje korporativno varnost v najširšem pomenu besede kot »dejavnost, ki identificira in izvaja vse potrebne sistemske ukrepe za obvladovanje varnostnih tveganj v posamezni organizaciji. Kot taka predstavlja eno izmed temeljnih funkcij za delovanje organizacije in se za njeno učinkovito delovanje nujno izvaja $\mathrm{v}$ tesnem sodelovanju $\mathrm{z}$ vsemi drugimi najpomembnejšimi funkcijami $\mathrm{v}$ organizaciji. Celovito področje korporativne varnosti za ustrezno obvladovanje varnostnih tveganj v korporaciji nujno vključuje področje varnosti ter procesa neprekinjenega poslovanja in varnosti pri delu. Procesi zagotavljanja korporativne varnosti so nedeljiva celota krovnega modela upravljanja korporacij, ki se izraža skozi korporativno upravljanje in korporativno družbeno odgovornost. Predvsem zadnja postavlja korporativno varnost kot proces $\mathrm{v}$ širši okvir delovanja v razmerju korporacije do družbe kot celote, v okolju, v katerem ta deluje. Korporativna varnost je zaradi svoje večplastnosti in umeščenosti v širok spekter raznovrstnih procesov delovanja organizacij še bolj odvisna od uvajanja vedno novih spoznanj.«

Lobnikar (2011, str. 2) korporativno varnost opisuje kot »dejavnost, s katero v najširšem pomenu besede identificiramo in izvajamo vse potrebne sistemske ukrepe za obvladovanje varnostnih tveganj v posamezni organizaciji. Cilj korporativne varnosti je zagotavljanje delovanja integralnega varnostnega sistema in predstavlja eno od funkcij korporacije.«

$\mathrm{O}$ varnostnem menedžmentu v zasebnem varovanju, zlasti pa o varnostnem menedžmentu v gospodarskih in drugih organizacijah, se v javnosti, pa tudi v strokovnih krogih, malo govori. Prvič najbrž zato, ker tovrstni menedžment že kot izraz ni prodrl v retoriko komuniciranja, drugič pa zato, ker ima v organizacijskih in menedžerskih strukturah nizek status in zaradi tega zelo malo manevrskega prostora za vplive v procesih odločanja. To je seveda krivično, kajti konkurenčnost, poslovni rezultati in dodana vrednost so v marsičem odvisni tudi od urejenosti varnostnih mehanizmov (Vršec, 2010, str. 7).

Zavedati pa se je treba tudi dejstva, da na gospodarske subjekte, poslovne procese, logistiko, trženje, komuniciranje in kadrovske strukture preži veliko nevarnosti, groženj in tveganj iz globalnega, regionalnega in lokalnega okolja. To še zlasti velja za kritično infrastrukturo, v kateri bi morali lastniki in upravljavci poslovnih procesov, premoženja, kapitala, trga in sprememb razviti učinkovitejše varnostne mehanizme, ki jih profesionalno upravlja varnostni menedžment.

Korporativno varnost upravlja strateški varnostni menedžment skladno z zakonodajo, oceno ogroženosti, varnostno politiko in varnostnimi standardi ter z uporabo ustreznih metod obvladovanja varnostnih tveganj, po načelu preprečevanja škode in izgub ter visoke stopnje družbene odgovornosti. Varnostna funkcija ima v poslovnih procesih zelo pomembno mesto, saj se posredno ali neposredno povezuje z vsemi 
drugimi poslovnimi procesi v organizaciji. Če to analogno pretvorimo v pregled nosilcev posameznih funkcij, lahko trdimo, da je korporativnovarnostni menedžment, ki je nosilec varnostne funkcije, zelo tesno povezan z upravljavskimi strukturami v drugih poslovnih funkcijah v organizaciji. Ta povezanost torej obstaja tudi pri odnosu med korporativnovarnostnim menedžmentom in kadrovskim menedžmentom, ki po moji oceni najtesneje sodelujeta prav pri zagotavljanju ustrezno trdne organizacijske in $\mathrm{v}$ tem okviru posebej varnostne kulture.

Vršec (2010, str. 14) opredeljuje odgovore varnostnega menedžmenta na sodobne varnostne izzive, ki se multiplicirajo in prepletajo na globalni in regionalni ravni, zlasti v:

- posnetkih in analizah stanja trenutnih lastnih varnostnih sistemov;

- metodološko izostrenem pristopu k ocenjevanju ranljivosti in ogroženosti premoženja, osebja, kapitala ter izvirnega znanja;

- pripravi in implementaciji varnostnih politik;

- projektnem pristopu k upravljanju varnostnih in drugih tveganj;

- uvajanju varnostnih standardov;

- presojanju kakovosti varovanja v sklopu sistema vodenja kakovosti po standardih IS0 9000:2000-2008;

- selekciji pri izbiri zunanjih pogodbenih izvajalcev varovanja;

- vključevanju v izobraževalne programe, ki ponujajo novo znanje;

- prizadevanjih, da se v slovensko varnostno prakso uvede standard DIN 77200, najprej skozi postopek $\mathrm{v}$ pristojni instituciji in nato $\mathrm{v}$ zasebnem varovanju in varnostnih sistemih.

Z navedenimi aktivnostmi se varnostni menedžment aktivno vključi v premagovanje ovir in prizadevanja drugih dejavnikov razvoja korporativnovarnostnega menedžmenta.

Čaleta (2011, str. 41) trdi, »da so procesi zagotavljanja korporativne varnosti nedeljiva celota krovnega modela upravljanja korporacij, ki se izraža skozi korporativno upravljanje in korporativno družbeno odgovornost. Predvsem zadnja postavlja korporativno varnost kot proces $\mathrm{v}$ širši okvir delovanja v razmerju korporacije do družbe kot celote v okolju, v katerem ta deluje.«

\section{Varnostna kultura}

Odnos do varnostne paradigme se je v zadnjih tridesetih letih precej spremenil. Od poudarjanja pretežno tehničnega vidika se je pozornost preusmerila najprej na človeške napake in nato na varnostni menedžment ter varnostno kulturo. Rečemo lahko, da je prepoznana vloga organizacijskih dejavnikov pri varnosti tako imenovano tretje obdobje varnosti, če so bile varnostne tehnologije prvo in človeški dejavniki drugo obdobje (Mengoli in Debarberis v Rančigaj, 2010, str. 21-22). Varnostna kultura je pomemben varnostni dejavnik celovitega integralnega varnostnega sistema organizacije. Opredelimo jo lahko kot skupek odgovornih in sprejetih vrednot, zavedanja in načinov vedenja vseh, ki sodelujejo v posameznem sistemu. V idealnem smislu 
je opredeljena kot odprta kultura, ki naj bi temeljila na zaupanju, poštenju, dobri komunikaciji, uspešnem sodelovanju, dobrem gospodarjenju, temelječ na spoštovanju osebne varnosti in varnosti celotne organizacije. Varnostna kultura naj bi bila integrirana v vsako aktivnost organizacije, njen proces naj bi bil usklajevan in voden, njeno učinkovitost pa je treba spremljati in dopolnjevati. Večina avtorjev, ki proučuje to področje varnosti, meni, da je varnost v osnovi vprašanje za menedžment (Biringer, Matalucci, O Connor, 2007, str. 35-39).

Sodobne in prodorne organizacije spodbujajo inovativnost, odprtost in kompetentnost zaposlenih. Uresničevanje take vizije prinaša številna tveganja, med katerimi je vse bolj očitno varnostno tveganje. Odgovor ponuja celovit varnostni sistem, ki namenja poseben poudarek zaščiti znanja in poslovnih skrivnosti ter temelji na profesionalnem notranjem nadzoru in reviziji. Varnostna kultura se lahko oblikuje le s spodbujanjem varnostnih interesov zaposlenih.

Vzvodi kadrovskega menedžmenta predstavljajo tiste mehanizme v organizaciji, s katerimi lahko lastniki oziroma vodje organizacije bistveno vplivajo na stopnjo varnostne kulture. Varnostna zavest zaposlenih je poleg tehničnih rešitev nujni pogoj za zagotavljanje čim boljše varnosti in gospodarske odličnosti podjetja. Sistemski pristop k oblikovanju varnostne kulture in dvigu varnostne zavesti temelji na komunikaciji, varnostnih postopkih in uresničevanju normativnega okvira. Poleg pravnih in postopkovnih dejavnikov so najpomembnejše gibalo varnostne kulture komunikacija in medosebni odnosi. Pri varnostni kulturi gre predvsem za človekovo sposobnost dojemanja resničnih nevarnosti in tveganj, razumevanje nujnosti obstoja državnih ter civilnodružbenih varnostnih mehanizmov in instrumentov ter pripravljenost za njihovo sodelovanje in žrtvovanje (Sotlar, 2000). Turner in sodelavci (1989 v Cooper, 2000) definirajo varnostno kulturo kot zbir prepričanj, norm, vedenj, vlog in socialnih ter tehničnih praks, ki so povezane z minimaliziranjem izpostavljenosti (zaposlenih, menedžerjev, strank in družbe) okoliščinam, ki se zdijo nevarne oziroma škodljive.

Ambrož (1999, str. 1) varnostno kulturo opredeljuje kot »splet v preteklosti uspešnih načinov reševanja varnostnih problemov, ki se uporabljajo za reševanje prihodnjih varnostnih problemov«. Varnostna kultura prav tako predstavlja »splet vrednot, prepričanj, simbolov in načinov za reševanje varnostnih problemov, ki so podlaga za odgovorno varovanje ljudi, poslovnih procesov in materialnih ter intelektualnih virov organizacije. Opredeljena je z značilnostmi delovnega okolja ter vpliva na zaznavo in ravnanje zaposlenih glede pomembnosti, ki je v organizaciji namenjena varnosti« (Ambrož, Mihalič in Ovsenik, 2000, str. 214). Vršec (2003, str. 38) še dodatno razširja definicijo varnostne kulture v smeri, da je »varnostna kultura državljanov, lastnikov, menedžmenta in drugih odgovornih oseb vrednota, ki nadgrajuje druge temelje sistema nacionalne varnosti. Gre za zavest, da ima vsakdo pravico in dolžnost poskrbeti za svojo varnost in hkrati prispevati $\mathrm{k}$ varnosti bivalnega, delovnega, poslovnega in širšega okolja.« Vodstvo organizacije mora na individualni in kolektivni ravni ozaveščati vse zaposlene in tako dvigovati varnostno kulturo na 
čim višjo raven (Whitman, 2005, str. 21). Borjesson (2006, str. 23) trdi, da »morajo biti v proces doseganja visoke stopnje varnostne kulture vključeni vsi zaposleni, pri čemer varnost predstavlja njihovo temeljno vrednoto«.

\section{UPORABLJENE METODE}

Skozi analizo problematike želimo v prispevku dokazati vlogo, ki jo ima kadrovski menedžment pri upravljanju korporativne varnosti v organizacijah. Čeprav korporativno varnost upravlja strateški varnostni menedžment, ki ta proces izvaja skladno z zakonodajo, oceno ogroženosti, varnostno politiko in varnostnimi standardi, ima v celovitem sistemu tudi kadrovski menedžment zelo pomembno vlogo. Zaradi navedenega želimo v prispevku analizirati, kje so tista stičišča, v katerih se procesa kadrovskega in varnostnega menedžmenta dopolnjujeta oziroma eden brez drugega ne moreta zagotoviti ustreznega obvladovanja varnostnih tveganj v okolju delovanja korporacije oziroma organizacije. Zagotavljanje visoke stopnje varnostne kulture je eden tistih procesov, ki zahteva sistematično delovanje obeh prej navedenih funkcij. Vse to je pogoj za zagotovitev ustreznega obvladovanja varnostnih tveganj, po načelu preprečevanja škode in izgub ter visoke stopnje družbene odgovornosti. V tem procesu se prepletajo vloge različnih subjektov, od lastnikov, upravljavcev, nadzornikov in varnostnih ter kadrovskih menedžerjev pa vse do vsakega posameznika, ki deluje v tem okolju. Delovanje tega dela lažje zagotavljamo v večjih korporacijah ali organizacijah. Večja težava so majhna ali srednje velika organizacijska okolja, ki si težko privoščijo stalno delujoč strukturiran sistem kadrovskega in varnostnega menedžmenta.

Za raziskavo problematike bomo uporabili temeljno hipotezo, ki se glasi: »Kadrovski menedžment ima pomembno vlogo pri zagotavljanju ustrezne ravni varnostne kulture v korporativnovarnostnem okolju.«

Pri proučevanju različnih virov informacij smo sistematično in postopno analizirali podatke, ki so bistveni za opredelitev problema in iskanje rešitve. $Z$ analizo in pregledom trenutnega stanja in raziskav na proučevanem področju smo poskušali opredeliti najpomembnejše ugotovitve, s katerimi bomo lahko potrdili ali zavrgli postavljeno hipotezo.

Pri analizi bodo potrebne določene omejitve, saj gre zaradi obširnosti za precej zapleteno problematiko. Zaradi navedenega smo si v aplikativnem delu prispevka pomagali s strukturiranim intervjujem z izbranimi sogovorniki iz šestih organizacijskih okolij, ki delajo na raziskovanem področju. S svojim prispevkom želimo posebej opredeliti določene nove pristope na področju zagotavljanja višje stopnje varnostne kulture v organizacijah korporativnega okolja.

Pri proučevanju teme in problematike $\mathrm{v}$ prispevku smo uporabili različne metode raziskovanja. Tema je interdisciplinarne narave, kajti kadrovski in varnostni sistem se v splošnem delu naslanjata na organizacijsko in ekonomsko-poslovno znanje, v 
konkretnem pa na pravno, kadrovsko in varnostno stroko ter na standarde. Tako so bile $\mathrm{v}$ procesu izdelave teoretičnega dela uporabljene metode, kot so obdelava problema v smeri od splošnega h konkretnemu (dedukcija), kakovostna analiza pridobljenih podatkov, informacij in gradiva, analiza kadrovskih in varnostnih procesov, analiza vsebine - pregled in študij domače ter tuje literature, ki se nanaša na organiziranost kadrovskih in varnostnih sistemov v podjetjih ter njihov vpliv na zagotavljanje ustrezne stopnje varnostne kulture, in sinteza ugotovitev, spoznanj ter dognanj.

V empiričnem delu prispevka smo za dokazovanje postavljenih hipotez opravili strukturirani intervju - anketiranci so bili iz vrst kadrovskega in korporativnovarnostnega menedžmenta. Iz tega izhaja, da pri obdelavi zbranih podatkov niso bile uporabljene matematično-statistične metode, temveč kakovostna (vsebinska) razlaga ugotovitev, spoznanj in dognanj.

Za doseganje teoretičnih spoznanj in poznejše preverjanje hipotez so v empiričnem delu prispevka predstavljeni rezultati intervjuja. Kot je bilo že navedeno, je bil izveden intervju s strokovnjaki iz šestih organizacijskih okolij. Trije namreč prihajajo z delovnega področja kadrovskega menedžmenta, trije pa iz okolja korporativnovarnostnega menedžmenta. Organizacije, iz katerih prihajajo omenjeni strokovnjaki, so bile izbrane načrtno tako, da obsegajo vse tri kategorije gospodarske organiziranosti v Republiki Sloveniji, in sicer mikro podjetniško okolje, kategorijo majhnih in srednjih organizacij, dve veliki mednarodni korporaciji s sedežem $\mathrm{v}$ Republiki Sloveniji, mednarodno korporacijo s sedežem v tujini in večjo organizacijsko obliko (ministrstvo) s področja državne uprave.

Strukturirani intervju je bil sestavljen iz vprašalnika, ki je vseboval vprašanja odprtega tipa. Za vprašanja odprtega tipa smo se odločili predvsem zato, ker gre pri organizacijah za precejšne posebnosti, povezane z dejavnostjo, okoljem delovanja in seveda z organizacijsko strukturo (velikostjo). Vprašanja te vrste so bila nujna, da so lahko intervjuvanci podrobneje pojasnili okoliščine, ki so pomembne za razumevanje dejavnikov in ukrepov za doseganje ustrezne stopnje varnostne kulture.

Iz tega izhaja tudi, da pri obdelavi zbranih podatkov ne bodo uporabljene matematično-statistične metode, temveč kakovostna (vsebinska) razlaga ugotovitev, spoznanj in dognanj. To je večplastna problematika, ki je nikakor ni mogoče obravnavati samo iz enega zornega kota, zato bo treba uporabiti interdisciplinarni pristop.

Intervju je vseboval vprašanja:

- Kakšne sistemske mehanizme uporabljate v vaši organizaciji za obvladovanje varnostnih tveganj?

- Ali v organizaciji obstaja krovna varnostna politika in ali vsebuje kakšne poudarke, povezane z varnostno kulturo zaposlenih?

- Ali imate v organizaciji ustanovljen varnostni svet oziroma na katerem koordinacijskem telesu se vodstvo seznanja $\mathrm{z}$ varnostnimi vprašanji in rešitvami $\mathrm{v}$ organizaciji? 
- Kdo je po vašem mnenju v organizaciji nosilni organ, ki je odgovoren za stanje varnostne kulture v organizaciji?

- Ali bi lahko ocenili, da v vašem podjetju vodstvo uveljavlja spremembe s svojim zgledom?

- Nam lahko zaupate svojo oceno o stanju varnostne kulture v vaši organizaciji?

- Kateri so po vaši oceni dejavniki, ki najbolj vplivajo na stopnjo varnostne kulture v organizaciji?

- Je v vaši organizaciji dovolj usposabljanj in izobraževanj, ki bi jih lahko povezali s povečevanjem varnostnega zavedanja? (Prosim, opredelite, kakšnih).

- Ali v kadrovskem procesu izbire kandidatov za zaposlitev preverjate tudi varnostne dejavnike in ali v kadrovski postopek vključujete tudi predstavnike s področja korporativne varnosti?

\section{REZULTATI}

Iz analize odgovorov je razvidno, da različne organizacije različno dojemajo pomen celovitega obvladovanja varnostnih tveganj in s tem še posebno pomen varnostne kulture v svojih okoljih in se zaradi svojih posebnosti tega vprašanja lotevajo zelo različno. V manjših organizacijah je zaznati težave s kadrovskimi in finančnimi viri, predvsem s stališča bolj organiziranega pristopa k vzpostavitvi mehanizmov, ki bi se v strukturi organizacije bolj sistematično ukvarjali z dvigovanjem varnostne kulture med zaposlenimi. V velikih organizacijah, predvsem izstopajo tiste, ki delujejo $\mathrm{V}$ zapletenem mednarodnem okolju, organizacijsko namenjajo pomembno pozornost varnosti s poudarkom na varovanju poslovnih skrivnosti, patentov in najpomembnejših konkurenčnih prednosti ter tako tudi na nujnosti ustrezne stopnje varnostne kulture zaposlenih. V mednarodni organizaciji kakor tudi v obeh slovenskih organizacijah, ki delujeta $\mathrm{v}$ mednarodnem okolju, sta varnostna kultura in varnostno zavedanje prepoznana in spodbujana kot pomembna vrednota $\mathrm{v}$ organizaciji. V vseh velikih organizacijah obstajajo strateški dokumenti, povezani z vsebino krovne varnostne politike, in so podlaga za izdelavo pravilnikov in navodil na nižjih ravneh delovanja. Posebno v organizacijski obliki državne uprave je temu normativnemu delu namenjeno razmeroma veliko pozornosti. Večjo težavo je v tem okolju zaznati v fazi izvajanja vseh predpisov v praksi. Varnostna kultura tudi ni prepoznana kot ena izmed pomembnih vrednot med zaposlenimi. V manjših organizacijskih strukturah imajo racionalnejši podjetniški pristop s čim manjšim predpisovanjem določenih normativov vedenja. Okolje je zelo tekmovalno in usmerjeno v doseganje ciljev. Zaradi majhnosti kolektiva medsebojni odnosi temeljijo na razmeroma visoki stopnji zaupanja, ki ne daje toliko pomena formalnim nadzornim mehanizmom, temveč bolj temelji na medosebni interakciji. Varnostne kulture zaposlenih ne poznajo pod osnovnim pojmom, vendar pa se je skozi pogovor razumelo, da zaposleni v manjših organizacijah prepoznajo nujnost varnega delovnega okolja in s tem njihove vloge pri zagotavljanju tega cilja. Mogoče je nekoliko težaven del povezan z varovanjem pomembnih informacij, patentov in drugih pomembnih podatkov, saj bi lahko odtekanje konkurenci pomenilo zmanjševanje konkurenčnih prednosti na tržišču. 
Kadrovskim procesom in izboru ustreznega kadra z varnostnega stališča v mikrookoljih, majhnih in srednjih okoljih ne namenjajo dovolj velike pozornosti in kadrovski postopek temelji predvsem na dokazilih o referencah in opravljenem osebnem intervjuju. V organizacijski obliki javne uprave in v slovenskih korporacijah temu namenjajo določeno pozornost prek dokazil o nekaznovanosti, v mednarodnih korporacijah pa temu namenjajo pomembno pozornost tudi prek drugih dokazil, ki dokazujejo, da je oseba vredna zaupanja, še posebno pri delovnih mestih strateškega menedžmenta, razvojnih inženirjih in drugih pomembnih kadrih. Pri analizi odgovorov, kdo je v organizaciji odgovoren za stanje varnostne kulture v organizaciji, so bili odgovori zelo različni, od direktorjev na mikroravni in srednji ravni do varnostnih struktur v organizacijskih oblikah državne uprave, pri slovenskih korporacijah pa je bila dodana še odgovornost strateškega vodstva. Samo v mednarodnih organizacijah je bilo poudarjeno, da gre tukaj za več ravni odgovornosti, med katerimi je imel svoje mesto tudi kadrovski menedžment. Predvsem v organizaciji državne uprave je bilo prepoznati odsotnost potrebe po sodelovanju med različnimi deli $\mathrm{v}$ strukturi organizacije v smeri zagotavljanja boljše stopnje varnostne kulture zaposlenih. Organizacije, ki so pretežno usmerjene v mednarodno okolje, pa so bile prisiljene urediti svojo organizacijsko strukturo v smeri večje prožnosti in nujnega medsebojnega sodelovanja. Dodatno to zagotavljajo z uveljavljanjem različnih orodij s področja standardizacije procesov, ki imajo v svoji vsebini tudi pomembne dele, povezane $\mathrm{z}$ medsektorskim sodelovanjem v organizaciji. To dejstvo je bilo razbrati tudi iz vprašanj, povezanih $\mathrm{z}$ oceno stopnje varnostne kulture $\mathrm{v}$ organizaciji. V organizacijah z urejeno lastniško strukturo in z menedžmentom, ki vodi organizacijo, usmerjeno pretežno v mednarodno okolje, je bilo razbrati, da gre za ustrezno visoko stopnjo varnostne kulture pri zaposlenih. Slabše so to stanje ocenjevali intervjuvanci iz organizacijskih oblik državnega okolja in organizacij, ki so usmerjene bolj $\mathrm{v}$ delovanje $\mathrm{v}$ nacionalnem okolju. Vodstvo in njegovo vodenje $\mathrm{z}$ zgledom sta bila pri vseh anketirancih prepoznana kot izredno pomemben dejavnik za uveljavljanje zavedanja o pomenu varnostne kulture kot pomembne vrednote v organizaciji. Seveda so bili odgovori različni o vlogi vodstva, vsem pa je bilo skupno, da bi moralo biti vodstvo v tem okviru še bolj dejavno. Strateški menedžment, ki nima izkušenj s tega področja ali ustreznega znanja, je v večini primerov tisti prvi signal, da v organizaciji temu področju ne namenjajo ustrezne pozornosti. To je bilo razbrati tako na mikro- kakor tudi na makroorganizacijski ravni intervjuvanih predstavnikov. To je tudi eden pomembnih dejavnikov, ki so ga prepoznali praktično vsi sogovorniki. Naslednji pa je vsekakor proces usposabljanja in izobraževanja, ki je največkrat zelo otežen predvsem zaradi vedno večje dinamike dela, novih organizacijskih oblik, ki predvsem poudarjajo tekmovalnost in cilje, na drugi strani pa vedno manj pozornosti namenjajo kolektivnemu duhu organizacij. Poleg tega so bile izpostavljene tudi kadrovske težave, povezane z ustreznimi strokovnjaki v organizacijskih strukturah, ki bi morali imeti ustrezno znanje in izkušnje iz te organizacije, da bi lahko v celoti izvajali take oblike izobraževanja in usposabljanja. V tem okviru so bile izpostavljene tudi finančne težave, ki vedno bolj omejujejo pošiljanje zaposlenih na oblike izobraževanj in usposabljanj, ki jih izvajajo zunanji izvajalci in ponudniki. $\mathrm{V}$ mednarodni organizaciji je intervjuvani sogovornik poudaril, da je v tem primeru 
pomembno tudi selektivno iskanje ustreznega kadra za določena mesta, na katerih je stopnja varnostne kulture prepoznana kot ena izmed pomembnih značilnosti. S tega stališča imajo kadri, ki prihajajo iz organizacij z urejenim sistemom obvladovanja varnostnih tveganj s poudarkom na ustrezni ravni varnostne kulture, lahko določeno konkurenčno prednost pred drugimi. Taka oseba je namreč že ustrezno varnostno formirana in se mora skozi proces uvajanja le še prilagoditi na posebnosti organizacije, v kateri trenutno deluje. Tudi drugi v organizacijah, v katerih skozi kadrovski proces tej vsebini ne dajejo dovolj poudarka pri izbiri kadra, so se strinjali, da je z ustreznim načinom kadrovanja mogoče rešiti veliko težav, ki se na področju povečevanja varnostne kulture pozneje pojavljajo v organizacijah. V vseh treh organizacijah, ki so pretežno usmerjene v mednarodno okolje, so sogovorniki poudarjali vedno večji pomen interaktivnega izobraževanja zaposlenih na daljavo, in sicer na delovnem mestu ali na drugih oddaljenih lokacijah. Kot dejavnik, ki ima pomemben vpliv, so bile izražene tudi predhodne izkušnje zaposlenih v organizaciji s posameznimi varnostnimi katastrofičnimi dogodki, ki so se v organizaciji zgodili v preteklosti. V to so vključeni naravne nesreče, industrijske nesreče, teroristični napadi, ugrabitve in izsiljevanja ter druga kriminalna dejanja. Slovenija je trenutno še vedno dovolj varno okolje, da predstavniki slovenskih organizacij temu v svojih odgovorih niso namenjali dovolj velike pozornosti. Predstavnik mednarodne korporacije pa je temu namenil posebno pozornost in poudaril, da so prav taka dejanja in travmatične izkušnje, ki so jim bili priča nekateri zaposleni in seveda prek njih tudi drugi, v njihovih okoljih proces zagotavljanja obvladovanja tveganj potisnili v ospredje potreb in vrednot.

Organizacijsko klimo so vsi prepoznali kot pomembno dejstvo, ki ima prav tako pomemben učinek na zadovoljstvo zaposlenih z delovnim okoljem in posredno tudi na njihovo pripravljenost za močnejše sprejemanje vrednot organizacije. V odgovorih posameznih strokovnjakov, ki so v svojih okoljih ocenjevali, da je varnostna kultura na nižji ravni, je bila organizacijska klima v organizaciji tudi eden izmed pomembnih dejavnikov, ki so ga povezovali z nižjo stopnjo varnostne kulture zaposlenih. V teh organizacijah je zaposleni preprosto niso vzeli za tisto okolje, za katero bi se bilo vredno dodatno potruditi od tistega nujnega in predpisanega.

\section{RAZPRAVA}

Kot je razvidno iz navedenega, je sistem zagotavljanja visoke stopnje varnostne kulture večplasten, saj nanj v organizacijah vpliva več vrst dejavnikov. V grobem jih lahko opredelimo kot organizacijske, kadrovske, finančne, psihološko-sociološke, pravne in varnostne dejavnike. Pri vzpostavitvi ustreznega okolja je treba upoštevati nekatere bistvene značilnosti varnostne kulture. V nadaljevanju navajam nekaj najpomembnejših značilnosti varnostne kulture:

- je koncept, ki je definiran na ravni skupine ali višje in se nanaša na skupne vrednote celotne skupine oziroma članov organizacije;

- ukvarja se s formalnimi varnostnimi zadevami v organizaciji in je ozko povezana, a ne omejena, z menedžerskim in nadzorstvenim sistemom; 
- poudarja prispevek vsakogar na vseh ravneh organizacije;

- ima vpliv na vedenje ljudi pri delu;

- navadno se odraža $\mathrm{v}$ nepredvidljivostih med sistemom nagrajevanja in varnim ravnanjem;

- kaže se v organizacijski pripravljenosti, da se razvija in uči iz napak ter nesreč;

- je razmeroma trajna, stabilna in odporna na spremembe.

Za doseganje ustreznega okolja v organizacijah je treba postaviti ustrezne sistemske temelje, ki posameznika vse od vstopa v organizacijo usmerjajo v dojemanje varnostnih pravil $\mathrm{v}$ organizaciji kot nekaj samoumevnega in nujnega za učinkovito delovanje organizacije in posameznika v organizaciji. Seveda je s tem tesno povezana tudi organizacijska klima $\mathrm{v}$ delovnem okolju, $\mathrm{v}$ katerem zadovoljen posameznik pomeni največji kapital organizacije tudi v smeri večje produktivnosti in boljših rezultatov dela. Celoten proces doseganja ustrezne stopnje varnostne kulture se začne že pri prvem temeljnem mejniku, ki ga lahko opredelimo v trenutku, ko posameznik vzpostavi osnovno interakcijo z okoljem svoje bodoče organizacije. Vstop v organizacijo da posamezniku prvi signal, v kakšno organizacijo prihaja, kaj je v tej organizaciji dovoljeno, kakšni so pravila in organizacijske vrednote ter katere stvari so pozitivno vrednotene. V urejeni organizaciji, v kateri ima varnostna kultura ustrezno mesto in stopnjo, posameznik te vrednote zavedno in nezavedno ponotranji in vzame za svoje, zato sta organiziran sprejem posameznika in seznanitev $\mathrm{z}$ varnostnimi predpisi zelo pomembna. V organizacijskih okoljih, v katerih temu ne namenjajo dovolj velike pozornosti, se lahko zgodi, da novi člani organizacije kmalu postanejo člani kolektiva z najnižjo stopnjo varnostne kulture, saj jo ob svojem prihodu v organizacijo niso prepoznali kot pomembno. To je še posebno izrazito pri mlajših osebah, pri katerih je to njihova prva zaposlitev. Ti namreč nimajo možnosti primerjati stanja $v$ drugih organizacijskih okoljih. Na doseganje ustrezne stopnje varnostne kulture $\mathrm{v}$ organizacijah negativno vpliva dejstvo, da živimo v globalnem gospodarskem okolju, v katerem je posebej izražena potreba po mobilnosti delovne sile. Situacije, ki smo jih poznali pred več kot 30 leti, ko je oseba lahko opravila svojo celotno poklicno kariero v eni organizaciji, so posebno s stališča zagotavljanja varnostne kulture pred vodilni menedžment postavljale zahtevno nalogo. Varnostna kultura je namreč dolgotrajen proces, ki ga ni mogoče doseči v zelo kratkem časovnem obdobju. Osebe, ki prihajajo iz organizacij, v katerih je bila varnostna kultura visoko na lestvici pomembnih vrednot organizacije, tudi v novem delovnem okolju ne bodo imele večjih težav s prilagajanjem in sprejemanjem varnostnih pravil. Večjo težavo bodo za nove delodajalce pomenile osebe, ki prihajajo iz organizacijskih okolij, v katerih temu niso namenjali dovolj velike pozornosti. Zaradi dolgotrajnosti procesov dvigovanja varnostne kulture pri takih osebah lahko ti postanejo moteč element v organizaciji. Tako se pri takih osebah močno poveča tveganje za odtekanje pomembnih informacij in nespoštovanje varnostnih pravil, ki bi lahko pomenila tudi škodne dogodke $\mathrm{z}$ večjimi posledicami, predvsem v organizacijah, ki obvladujejo procese kritične infrastrukture. Posebno v tem delu ti dejavniki pomenijo pomembne izzive za varnostne in kadrovske strokovnjake ter jih silijo $\mathrm{v}$ še tesnejše sodelovanje. V kadrovskem procesu pridobivanja novega kadra bo to 
področje poleg preostalih postalo eno izmed najpomembnejših za sprejem posameznika v organizacijo, v kateri so zahteve za dojemanje varnostne kulture postavljene zelo visoko.

Dejavnik, ki zelo močno vpliva na vse druge procese, povezane z uveljavljanjem in dvigovanjem varnostne kulture v organizaciji, je zavedanje vodstva o pomenu tega procesa. Menedžment vse od strateške ravni navzdol na vseh ravneh v okolje organizacije predaja zavedna in nezavedna sporočila, da je $\mathrm{v}$ organizaciji, ki jo vodi, varnost kot vrednota spoštovana in ji je dana velika pozornost. To so signali, ki zaposlene v organizaciji usmerjajo v izvajanje njihovih ravnanj in dejanj, ki so skladni s splošno sprejeto varnostno kulturo v organizaciji. Strateški menedžment kaže svojo zavezanost tej vrednosti že s sprejetjem strateških dokumentov oziroma krovne varnostne politike organizacije. Za zagotavljanje obvladovanja varnostnih tveganj pa ni dovolj samo deklarativno podpiranje ukrepov, temveč predvsem vodenje $\mathrm{z}$ zgledom. V večini organizacij, v katerih je stanje varnostne kulture nizko, se je razkroj sistema začel z nespoštovanjem strateškega menedžmenta in tistih predpisanih normativov ali vrednot, ki so jih sami sprejeli v svojih organizacijah. Ker temu ni sledila učinkovita vpeljava, tudi in predvsem z metodo vodenja z lastnim zgledom, se je nespoštovanje predpisanih normativov kmalu razširilo $\mathrm{v}$ vse pore organizacije. Ko se procesi začnejo premikati v smeri razkroja sistema, jih je zelo težko obrniti spet v pravo smer. Te nevarnosti se strateško vodstvo $\mathrm{v}$ organizacijah premalo zaveda. Poznamo pa tudi primere, v katerih je strateško vodstvo, predvsem v organizacijah, v katerih zasede položaje na novo, zelo motivirano za uveljavljanje novih standardov na področju varnostne kulture. Toda če ne upošteva dejstva, da obsežnejše spremembe brez aktivnega vključevanja in motivacije srednjega menedžmenta niso mogoče, pri tem navadno ni uspešno. Tudi ti primeri so v praksi zelo pogosti in nam kažejo na dejstvo, da je varnostna kultura mreža zelo občutljivih dejavnikov, ki se prepletajo skozi celotno organizacijo in imajo na različnih ravneh tudi različne posebnosti. Pomembno pa je zavedanje, da lahko neupoštevanje posebnosti teh dejavnikov na posameznih ravneh povzroči negativne posledice na celotni organizacijski mreži. Z odločnostjo vodstva organizacije, da v organizaciji uveljavi ustrezno stopnjo varnostne kulture, je zelo tesno povezan tudi nadzorni mehanizem. Ta je nujen vzvod vodstva pri zaznavanju stopnje izvajanja načrtovanih rešitev za doseganje ustrezne stopnje varnostne kulture v organizaciji. Mehanizmi omogočajo tudi identifikacijo deviantnosti v organizaciji in možnost izvedbe nujnih ukrepov za odpravo pomanjkljivosti. Dejstvo je, da je vsak sistem predpisov in pravil učinkovit toliko, kot je učinkovit sistem nadzora v organizaciji. Nadzor vodstvu omogoča, da z določenimi podatki in informacijami, ki so nujni za korigiranje predpisanega sistema, zagotovi izvajanje sankcioniranja tistih posameznikov, ki se nikakor niso sposobni ali pripravljeni podrediti temeljnim pravilom delovanja v organizaciji.

Nadzorne mehanizme lahko najdemo v različnih oblikah in niso nujno usmerjeni samo v represivno korekcijo ugotovljenih deviantnosti, temveč jih menedžment uporablja predvsem za načrtovanje in izvajanje preventivnih aktivnosti, ki bodo $\mathrm{v}$ 
prihodnje preprečile ponavljanje nepravilnosti. V tem okviru ima učenje iz izkušenj oziroma storjenih napak, ki se uporabi za preventivno ozaveščanje članov organizacije, zelo pomembno vlogo. Posamezniki in predvsem organizacije, ki so se pripravljeni učiti na storjenih napakah in so sposobni učenja na analizi tujih napak, so uspešni pri uveljavljanju ustrezne stopnje varnostne kulture v svojem organizacijskem okolju. V učinkovitih organizacijskih okoljih imajo zato ustanovljen varnostni forum, v katerem se strateško vodstvo skupaj s korporativnovarnostnim menedžmentom in drugimi strukturami $\mathrm{v}$ organizaciji ukvarja $\mathrm{z}$ varnostnimi vprašanji in jih tudi sprotno rešuje. Pomemben del tega mehanizma je tudi, da imajo zaposleni po določenih vzvodih možnost, da na varnostni forum naslavljajo svoje predloge, pobude in izkušnje, tudi kadar gre za varnostne kršitve, seveda v smeri izboljšanja stanja. Naloga foruma je med drugim tudi, da se seznani z analizo, ki jo prej izvedejo ustrezne službe ob vsaki varnostni kršitvi, in na podlagi tega sprejme korektivne ukrepe, ki bodo v prihodnosti preprečevali ponavljanje takih nepravilnosti.

Varnostni forum pa ima v organizacijah še dodatno lastnost, ki ima določen vpliv na stopnjo varnostne strukture v organizaciji. Ta se zrcali v nujnosti učinkovitega sodelovanja med strukturami v organizaciji, ki so neposredno ali posredno odgovorne za obvladovanje varnostnih procesov. Okolje, v katerem delujejo organizacije, je v zadnjem obdobju postalo zelo zahtevno, saj je dinamičnost vse večja, odvisni smo od informacijsko-komunikacijskih tehnologij, po drugi strani pa se pojavljajo vedno nove oblike tveganja in groženj, ki so po svoji obliki asimetrične in večplastne. To pomeni, da so tudi odgovori za ustrezno obvladovanje tveganj postali večplastni in jih nikakor ni mogoče izvajati samo v okviru korporativne varnosti, temveč to od organizacije zahteva učinkovito sodelovanje med različnimi strokovnimi organi. V tem okviru bi veljalo še posebej poudariti sodelovanje med procesi korporativne varnosti, kadrovskimi, pravnimi, finančnimi in informacijsko-komunikacijskimi procesi. Neustrezna raven sodelovanja ima lahko za organizacijo zelo velike negativne učinke na področju sposobnosti obvladovanja tveganj, ki jim je izpostavljena organizacija, na drugi strani pa ima negativne učinke tudi na stopnjo varnostne kulture med člani organizacije. Uspešnega poslovanja organizacije si ni več mogoče zamisliti, če se vsi podporni procesi tvorno ne usmerjajo k podpori glavnega organizacijskega procesa in s svojim sodelovanjem ne omogočajo, da med temi procesi prihaja do čim manjših varnostnih praznin in nedorečenosti. Prav s tega stališča je varnostni forum za strateško vodstvo lahko učinkovit mehanizem, ki od vseh navedenih subjektov zahteva tesnejše sodelovanje in izmenjavo vseh informacij, ki so nujne za sistemski pristop h končnemu cilju, ki je celovito obvladovanje tveganj in nemoteno delovanje glavnega organizacijskega procesa organizacije.

Ustrezne stopnje varnostne kulture si v organizacijah ne moremo zamisliti brez nenehnega pridobivanja novega znanja. Model izobraževanja in usposabljanja mora posamezniku v organizacijskem okolju in tudi zunaj njega omogočati dovolj spodbud in možnosti za permanentno izobraževanje. Oblike izobraževanja in usposabljanja so lahko različne, in sicer v organizacijskem, vsebinskem in tudi motivacijskem smislu pristopa in izvedbe. Usmerjene so lahko neposredno na posameznika ali pa na širšo 
organizacijsko strukturo v okviru neke organizacije. Po vsebini so lahko neposredno povezane $\mathrm{z}$ varnostno problematiko ali pa je ta problematika posredno vtkana skozi izobraževanja in usposabljanja drugih vsebin. Nujno je, da temu procesu namenimo zadostno pozornost in da ga dojemamo kot tisto najpomembnejše za dolgoročno dvigovanje obsega znanja o obravnavani tematiki in s tem tudi nujni pogoj za dvigovanje stopnje varnostne kulture $\mathrm{v}$ organizaciji. Uvajanje novih rešitev je tako $\mathrm{s}$ tehničnega kot organizacijskega vidika nujno podvrženo predhodnemu usposabljanju in obveščanju vseh uporabnikov v organizaciji. Najbolj občutljiva stopnja pri uveljavljanju določenih novosti v sistem organizacije je lahko prav pomanjkljiva obveščenost ali znanje zaposlenih. Že tako se je treba zavedati, da je večina novosti sprejeta s kančkom nezaupanja in odpora, saj ruši ustaljene mehanizme delovanja, na katere so bili zaposleni navajeni. Če v tem okviru govorimo o uveljavljanju varnostnih pravil, ki lahko še dodatno omejujejo svobodo posameznikov, so take stvari lahko sprejete še z večjimi zadržki. Če procesom uveljavljanja ne sledijo tudi procesi obveščanja in usposabljanja, rezultati uvajanja novosti niso na želeni ravni, posredno pa se skozi te procese odraža tudi stopnja varnostne kulture. V organizacijah z višjo stopnjo varnostne kulture se novosti na področju novih varnostnih rešitev lažje in učinkoviteje uvajajo kot v organizacijah, v katerih je stopnja varnostne kulture in zavedanja nizka in je že zato ob novostih s področja obvladovanja tveganj pri zaposlenih prisoten odpor.

Kot organizacijo z učinkovito varnostno kulturo bi lahko opredelili organizacijo, ki ima:

- vzpostavljen sistem, ki zbira, analizira in razširja informacije o nesrečah, ki so se ali so se skoraj zgodile, kot tudi o rednih proaktivnih pregledih sistema;

- razvito kulturo poročanja, ljudje so pripravljeni prijaviti svoje napake, zmote in kršitve;

- kulturo zaupanja, v kateri ljudi spodbujajo in celo nagradijo, da seznanjajo druge z bistvenimi informacijami, povezanimi z varnostjo; ločnica med sprejemljivim in nesprejemljivim vedenjem je pri tem jasna;

- razvito prilagodljivost, ki se kaže v sposobnosti preoblikovati organizacijsko strukturo skladno z dinamičnimi zahtevami okolja (tako imenovana fleksibilna kultura);

- visoko stopnjo pripravljenosti in usposobljenosti analizirati varnostni sistem in izvesti spremembe, ko je nakazana potreba.

Kazalniki pozitivne varnostne kulture, ki organizacije ločujejo med seboj na uspešne in neuspešne, so:

- višji menedžment močno poudarja varnost kot del strategije obvladovanj tveganj, na primer minimaliziranje izgub;

- srednji menedžment in operativno osebje imata stvaren pogled na kratko- in srednjeročne nevarnosti, ki so povezane z organizacijskimi aktivnostmi;

- višji menedžment spodbuja nekaznovalno delovno okolje. Nekatere organizacije uporabljajo termin »pravična kultura« namesto nekaznovalna, ki pa ne pomeni imunitete pred kaznovanjem; 
- na vseh ravneh organizacije, ki vključujejo notranje in zunanje okolje, je prisotna zavest o pomembnosti pogovarjanja o varnostnih informacijah;

- imajo stvarne in učinkovite predpise, ki se nanašajo na nevarnost, varnost in morebitno škodo;

- zaposleni so dobro usposobljeni in razumejo posledice nevarnih dejanj;

- pojavnost tveganega vedenja je nizka;

- prisotna je varnostna etika, ki odvrača od tveganega vedenja.

V kratkem bi lahko strnili, da je korporativno varnost dolgoročno treba obravnavati načrtno, organizirano, usklajeno in ustrezno ciljno usmerjeno. V osnovi lahko poudarim te ključne dejavnike:

- zavedanje vodstev, da so potrebne spremembe (doseganje najugodnejšega razmerja med ravnjo prevzetega poslovnega tveganja in doseganjem postavljenega cilja);

- upravljanje varnosti je sestavni del kulture organizacije in je vpeto v vse pore delovanja organizacije;

- spremenjeno ravnanje poslovodstev, uprav in direktorjev ter uporaba novih metod in tehnik ravnanja s kadri (odgovornost menedžmenta za kadre);

- načrtno pridobivanje ustreznih znanja, sposobnosti in vedenja zaposlenih;

- nova organizacijska psihologija - spremenjeni odnos zaposlenih do sprememb v organizaciji.

Učinkovito upravljanje kadrovskega potenciala organizacije je tudi eden izmed temeljnih pogojev za ustvarjanje ustrezne organizacijske klime, ki je zelo tesno povezana tudi s stopnjo varnostne kulture v organizaciji. Boljša ko je organizacijska klima v organizaciji, bolj so posamezniki zadovoljni s svojim delovnim okoljem in lažje uveljavljajo svoje interese v taki organizaciji. Če so ti procesi usmerjeni v isto smer, za katero si prizadeva tudi organizacija, v kateri delujejo, je to ustrezen pogoj, da so taki ljudje tudi varnostno bolje ozaveščeni. Stopnjo varnostne kulture v takih organizacijah je lažje zagotavljati v navedenem okolju.

Skozi analizo problematike smo dokazovali vlogo, ki jo ima kadrovski menedžment pri upravljanju korporativne varnosti v organizacijah. Čeprav korporativno varnost upravlja strateški varnostni menedžment, ki ta proces izvaja skladno z zakonodajo, oceno ogroženosti, varnostno politiko in varnostnimi standardi, ima v celovitem sistemu tudi kadrovski menedžment zelo pomembno vlogo. Tako je ne nazadnje razvidno, da so dejavniki, ki močno vplivajo na varnostno kulturo, v večjem delu povezani tudi $\mathrm{s}$ kadrovskim procesom in $\mathrm{s}$ tega stališča zelo pomembni. V tem okviru velja poudariti nekaj najbolj izpostavljenih, kot so ustrezen izbor kadrovskega potenciala za delo v organizaciji ter procesi izobraževanja, usposabljanja in načrtovanja kadrovskih virov. Dinamičnost okolja in asimetričnost groženj, ki so jim danes izpostavljene organizacije, ne dopuščata več vodenja ločenih procesov v organizaciji. Organizacije, ki svojih struktur in predvsem procesov niso bile sposobne racionalizirati $\mathrm{v}$ smeri večje prožnosti in poudarjenega medsebojnega sodelovanja, izgubljajo konkurenčni boj na tržišču. Ta dejavnik oziroma potreba 
pa je zaobšla organizacije, ki so financirane iz državnega proračuna in v katerih do zdaj pritisk ni bil tako močan, da bi procese reorganizirali v smeri večjega sodelovanja oziroma $\mathrm{v}$ tem primeru proučevanja sodelovanja med kadrovskim in varnostnim menedžmentom. Podatki, dobljeni iz intervjujev, so pokazali tudi, da kadrovske in predvsem finančne zmožnosti močno vplivajo na ustrezen sistemski pristop obvladovanja tveganj in $\mathrm{v}$ tem okviru na ustrezno stopnjo varnostne kulture kot pomembnega pogoja za primerno odzivanje zaposlenih na varnostna tveganja in grožnje. V prispevku so bila večkrat opredeljena pomembna stičišča, v katerih se procesa kadrovskega in varnostnega menedžmenta dopolnjujeta oziroma eden brez drugega ne moreta zagotoviti ustreznega obvladovanja varnostnih tveganj $\mathrm{v}$ okolju delovanja korporacije oziroma organizacije. Zagotavljanje visoke stopnje varnostne kulture je eden tistih procesov, ki zahtevajo sistematično delovanje obeh prej navedenih funkcij.

Večja težava je pri majhnih ali srednje velikih okoljih, ki si težko privoščijo stalno delujoč strukturiran sistem kadrovskega in varnostnega menedžmenta.

Vse navedeno nakazuje, da lahko postavljeno hipotezo, da ima kadrovski menedžment pomembno vlogo pri zagotavljanju ustrezne ravni varnostne kulture $v$ korporativnovarnostnem okolju, ustrezno potrdimo.

Seveda pa se morajo strateška vodstva v organizacijah zavedati, da bodo predvsem $\mathrm{z}$ učinkovitim upravljanjem organizacij dosegla ustrezno raven medsebojnega sodelovanja in prepletanja procesov v smeri dvigovanja varnostne kulture. Spreminjanje varnostne kulture je večplasten in dolgotrajen postopek, ki ga ni mogoče načrtovati in predvsem doseči rezultate v zelo kratkem obdobju. Za uvajanje novih pristopov je potrebno precej tankočutnosti, ki zagotovi, da posamezniki v organizaciji spremembe vzamejo za svoje. Upajmo, da nam ne bo treba procesov dvigovanja varnostne kulture uveljavljati na tragičnih izkušnjah dogodkov, ki bi jih z ustreznim vedenjem in varnostnim ravnanjem v organizacijah preprečili. Ob tem se moramo zavedati, da življenje $\mathrm{v}$ tako dinamičnem okolju prinaša tveganja, ki jih v celoti nikoli ne moremo povsem odpraviti. Zaradi navedenega bomo vedno primorani tehtati med viri in še sprejemljivo ravnjo tveganja pri posameznih grožnjah, ki nas obkrožajo. Ob tem dejstvu pa ima varnostna kultura še pomembnejše mesto.

1. Ambrož, M., 1999. Varnostna kultura. V A. Andrej (ur.), Varnost in turizem, zbornik posveta, (str. 1-20). Ljubljana: Visoka policijsko varnostna šola.

2. Ambrož, M., Mihalič, T., Ovsenik, M., 2000. Varnostna kultura in sistem varovanja v organizaciji. Varstvoslovje, 2(3), str. 211-228.

3. Bertoncelj, B., 2012. The individual and security. V Čaleta, D., ur. Corporate security in global dynamic environment - challenges and risks. Ljubljana: ICS.

4. Biringer, B., E., Matalucci, R. V., O Connor, S. L., 2007. Security Risk Assessment and Management: A professional Practice Guide for Protecting Buildings and Infrastructures. New Jersey: John Wiley \& Sons. 
5. Borjesson, M., 2006. Survey and assessment of safety culture-a method proposal and the application of the model of two companies within the process industry. Master of science in Risk management and Safety Engineering at Lund Univeristy, Sweden. Pridobljeno na http://riskhantering.lth.selenglish/master s_thesis/.

6. Borodzicz, E., 2005. Risk, Crisis and Security Management. New York: John Wiley \& Sons.

7. Broder, J., F., 2006. Risk Analysis and the Security Survey. Boston: Oxford.

8. Cooper, K., 2000. Effective competency modeling \& reporting : a step-by-step guide for improving individual \& organizational performance. New York: AMACOM.

9. Cuming, M., W. 1994. The theory and practice of personnel management. Oxford: Butterworth-Heinemann.

10. Čaleta, D., 2008. Varovanje tajnih podatkov v demokratično družbi. V Jambrek, P., ur. Dignitas - Slovenska revija za človekove pravice, str. 249-265. Predoslje: Fakulteta za državne študije.

11. Čaleta, D., Shemella, P., 2011. Counter Terrorism Challenges regarding to process of Critical Infrastructure Protection. Ljubljana, Monterey: ICS in CCMR.

12. Čaleta, D., 2011. Varnost mojega podjetja. Podjetnik 11 (10), str. 40-41.

13. Čaleta, D., 2012. The role of geopolitics and geoeconomics in providing corporate security. V Čaleta, D., ur. Corporate security in global dynamic environment - challenges and risks, str. 11-25. Ljubljana: ICS.

14. Florjančič, J., Jesenko, J., Pagon, M., 1991. Izgradnja informacijskega modela kadrovske dejavnosti v podjetju (2. ponatis). Kranj: Moderna organizacija.

15. Florjančič, J., Ferjan, M., Bernik, M., 1999. Poglavja: Planiranje kadrov v podjetju, str. 29-107, Pridobivanje kadrov, str. 110-121, Izobraževanje in usposabljanje, str. 124-130. Planiranje in razvoj kadrov. Kranj: Moderna organizacija.

16. Florjančič, J., Bernik, M., Novak, V., 2004. Kadrovski management. Kranj: Moderna organizacija.

17. Landoll, D., 2005. The Security Risk Assessment Handbook: A Complete Guide for Performing Security Risk Assessment. Boston: Oxford.

18. Lipičnik, B., 1998. Ravnanje z ljudmi pri delu. Ljubljana: Gospodarski vestnik.

19. Lobnikar, B., Čaleta, D., Žaberl, M., Anžič, A., Rančigaj, K., 2009. Varnostna in organizacijska kultura $v$ Slovenski vojski z vidika upravljanja s tajnimi podatki: končno poročilo raziskovalne skupine Fakultete za varnostne vede. Ljubljana: FVV.

20. Lobnikar, B., 2011. Korporacijska varnost in vloga strateškega kadrovskega menedžmenta - predstavitev na posvetu z nazivom »Obvladovanje kadrov in njihov vpliv na zagotavljanje korporativne varnosti«z dne 10. 5. 2011. Ljubljana: ICS.

21. Merkač, Skok, M. 2005. Osnove managementa zaposlenih. Koper: Fakulteta za management.

22. Možina, S., Jereb, J., Florjančič, J. Svetic, A., 1998. Management kadrovskih virov. Ljubljana: Fakulteta za družbene vede.

23. Možina, S., 2002. Vodenje, vedenje. Ljubljana: Ekonomska fakulteta.

24. Rančigaj, K., 2010. Povezanost organizacijske in varnostne kulture v varnostni organizaciji (magistrsko delo). Ljubljana: FVV.

25. Sotlar, A., 2000. Is it necessary, ethical and time to (ex)change the traditional roles of the police and armed forces?. V Pagon, M., ur. Policing in Central and Eastern Europe. Ethics, integrity, and human rights, str. 311-319. Ljubljana: College of Police and Security Studies.

26. Vršec, M., 2003. Uvajanje sodobnih varnostnih mehanizmov v poslovne procese gospodarske družbe in gospodarske javne službe. Dnevi varstvoslovja, Bled: Visoka policijsko-varnostna šola. 
27. Vršec, M., 2010. Izzivi varnostnih managerjev. V Čaleta, D., ur. Upravljanje varnostnih tveganj povezanih z varovanjem kritične infrastrukture: Zbornik mednarodnega posveta s področja varnostnega managementa, str. 83-97. Ljubljana: Institut za korporativne varnostne študije.

28. Whitman, M., 2005. The culture of Safety: no one gets hurt today. The police chief, 72 (11), str. 20-24. 